\title{
QoS-aware Cross Layer Handover Scheme for High-Speed vehicles
}

\author{
Heba Nashaat \\ Electrical Engineering Department, Port Said University \\ Port Said, 42523, Egypt \\ [hebanashaat@eng.psu.edu.eg]
}

Received December 29, 2016; revised April 12, 2017; revised June 6, 2017; revised August 2, 2017; accepted September 15, 2017; published January 31, 2018

\begin{abstract}
High-Speed vehicles can be considered as multiple mobile nodes that move together in a large-scale mobile network. High-speed makes the time allowed for a mobile node to complete a handover procedure shorter and more frequently. Hence, several protocols are used to manage the mobility of mobile nodes such as Network Mobility (NEMO). However, there are still some problems such as high handover latency and packet loss. So efficient handover management is needed to meet Quality of Service (QoS) requirements for real-time applications. This paper utilizes the cross-layer seamless handover technique for network mobility presented in cellular networks. It extends this technique to propose QoS-aware NEMO protocol which considers QoS requirements for real-time applications. A novel analytical framework is developed to compare the performance of the proposed protocol with basic NEMO using cost functions for realistic city mobility model. The numerical results show that QoS-aware NEMO protocol improves the performance in terms of handover latency, packet delivery cost, location update cost, and total cost.
\end{abstract}

Keywords: High-Speed vehicles, NEMO BSP, Vehicular networks, QoS-aware NEMO protocol 


\section{Introduction}

High-Speed vehicles are becoming increasingly popular among long-distance travelers. Moreover, each user may require high quality connection and continuous internet access services.This constitutes one of the main challenges that networking researchers are facing nowadays to deal with the massive evolution of wireless networking technology, mobile services and applications. Vehicles perform handover frequently thus efficient handover is essential to meet the Quality of Service (QoS) requirements for real-time applications for High-Speed vehicles. The challenge is further expanded when the demand for mobility is not restricted on a single host. The Internet Engineering Task Force (IETF) working group has proposed Mobile IPv4 (MIPv4) and Mobile IPv6 (MIPv6) as the main protocols for supporting IP mobility to a single host or mobile node. Various enhancements to the MIPv6 protocol have been already proposed since it is believed that in certain cases Mobile IPv6 could result in a poor performance. These enhancements are Fast Mobile IPv6, Hierarchical Mobile IPv6 and Fast Hierarchical Mobile IPv6 [1-4].

Nevertheless, it is necessary to support the mobility of a complete network that moves collectively as a single unit such as on trains ,ships, buses and aircrafts. Therefore, IETF has proposed Network Mobility Basic Support Protocol (NEMO BSP) based on Mobile IPv6. The protocol uses sub-optimal routing that can disrupt all communications to and from the Mobile Network Nodes (MNN). Moreover, the overheads are amplified if mobile networks are nested. Therefore, a number of studies for enhancement of original procedures of NEMO have been introduced. These studies can be classified based on the objective of proposed protocols into three classes. Protocols in the first class attempt to solve nested mobile network situation to improve network-layer handover phase [5]. Second class protocols try to minimize handover latency by adopting the tentative Binding Update (BU) and eliminating the tunneling burden [6]. Protocols in third class try to overcome sub-optimal routing problem by using Route optimization concept to reduce packet transfer delay [7].

However, the demand for high-speed vehicles pushed recent researches into a new direction, such as [8]. In that research, the authors propose a cross-layer hierarchical network mobility framework for all-IP networks. It has no extra triangular route between an MNN and the CN. In [9], authors propose an LTE femtocell-based network mobility scheme to support seamless handover for high-speed rail systems. Another challenge is introduced in [10], as the research introduces the issue of long handover latency when the mobile devices move with vehicular speed. The paper proposes a system to resolve this issue by using an LTE femtocell based network mobility scheme by using multiple egress network interface to support seamless handover for a high-speed train and avoid packet loss in the network during handover.

Although most of those enhancements try to achieve seamless traffic, they do not consider MNN services level and do not guarantee QoS application requirements. This represents a problem for real-time applications that require QoS guarantees. Therefore, there are recent works that are trying to deal with QoS guaranteed service. As in [11], the authors introduce QoS-aware user association strategy to individual mobile station explicitly, aiming to minimize the network-wide packet delay. Moreover, other researches have been working to propagate this strategy in network mobility protocol. These researches suggest embedding QoS awareness concept in NEMO based networks. For example, authors in [12] exploit DiffServ depiction to pull off silky delivery of real-time transferring in heterogeneous network mobility. In [13], the paper proposes a scheme uses DiffServ model composite within NEMO 
to offer privilege. However, all protocols depending on DiffServ model have the same drawback; they do not provide an absolute guarantee of service especially when it is applied in a cellular network such as WiMAX. This paper addresses this inefficiency by proposing a QoS-aware NEMO that enhances QoS within NEMO environment by combining cross-layer mobility management and resource allocation. The proposed protocol does not depend on the underlying service, which makes it flexible to manage resources effectively, and compatible with the existing cellular networks. The contributions of this paper can be summarized as follows:

- Introducing a dynamic resource allocation procedure that takes into account allocating bandwidth to users based on QoS requirements as well as the wireless channel conditions.

- Combining fast handover techniques for NEMO over WiMAX technology. In which the proposed protocol does not replace the original handover mechanisms of the WiMAX standard. Instead, it tries to cooperate with the layer 2 mechanisms using cross-layer mobility management. Therefore, it can support connections with QoS considerations for mobile users.

- Presenting an analytical framework to perform a comprehensive cost function for the proposed protocol. It evaluates and compares the handover latency and signaling costs using; City Section Mobility Model (CSM).

The rest of this paper is organized as follows; Section 2 introduces NEMO BSP, while Section 3 represents QoS-aware NEMO protocol. The analytical framework is shown in Section 4. Section 5 presents the numerical results. Finally, the concluding remarks are given in Section 6.

\section{Architecture of NEMO BSP}

In NEMO BSP, Mobile Router (MR) ensures continuous connectivity of all the nodes inside the MNN even as the MR moves and changes its point of attachment to the internet. An MR has a unique IP address and has one or more prefixes that it advertises to the MNNs attached to it. MR provides complete transparency of network mobility to the MNNs. The MR establishes a bi-directional tunnel with its Home Agent (HA) to pass all the traffic between the MNN and the correspondent nodes. When an MR moves away from its home network and changes its point of attachment as in Fig. 1, it acquires a new care-of-address (CoA) from the visited network. Then, it sends a binding update to its HA; New cache entry binding MR's home address with its care-of-address is created. When a correspondent node (CN) sends data to an MNN, it is routed to the HA of MR. HA looks at its cache entry and forwards the packet to the MR using the bidirectional tunnel. Finally, MR receives the packet, decapsulates it, and forwards it for the MNN [5].

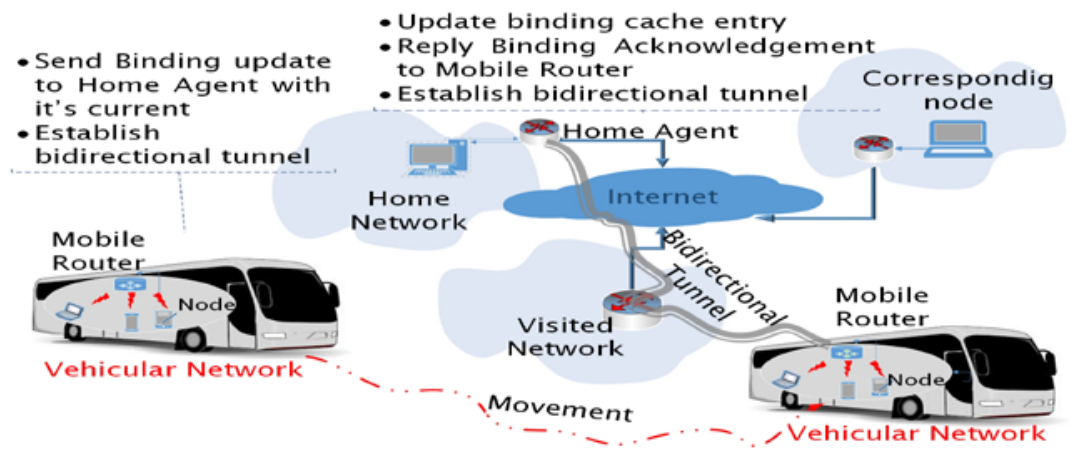

Fig. 1. Architecture of NEMO BSP [5] 
Fig. 2 shows the handover operation and its timing diagram in NEMO BSP. The handover delay is calculated as the time interval between the arrival of the last packet when the MR still connected with the Serving BS (SBS) and the arrival of the first MR data packet at the Target BS (TBS). In NEMO BS, after completing the link-layer handover, the MR sends a router solicitation (RtSol) immediately. It then receives the router advertisement (RtAdv) message broadcasted by the Target Acces Router (TAR) and configures its New CoA. Based on mobile network prefix (MNP) advertised by the mobile router, MR verifies the uniqueness of the NCoA by sending the Neighbor Advertisement (NA) to the TAR then receiving a Neighbor Advertisement ACKnowledgement (NAACK) [6].

The MR sends BU message to its home agent. Then, HA sends Binding Acknowledgement (BA) back to finish the location update procedure. When the MR changes its point of attachment, it also acquires a CoA from the visiting network and updates the binding cache of its home agent. Since the CoAs of MNNs remain unchanged, there is no need to send location update messages to the HA of the MNNs. Once the binding procedure is completed, a bi-directional tunnel between MR and HA is established based on IP-in-IP encapsulation.

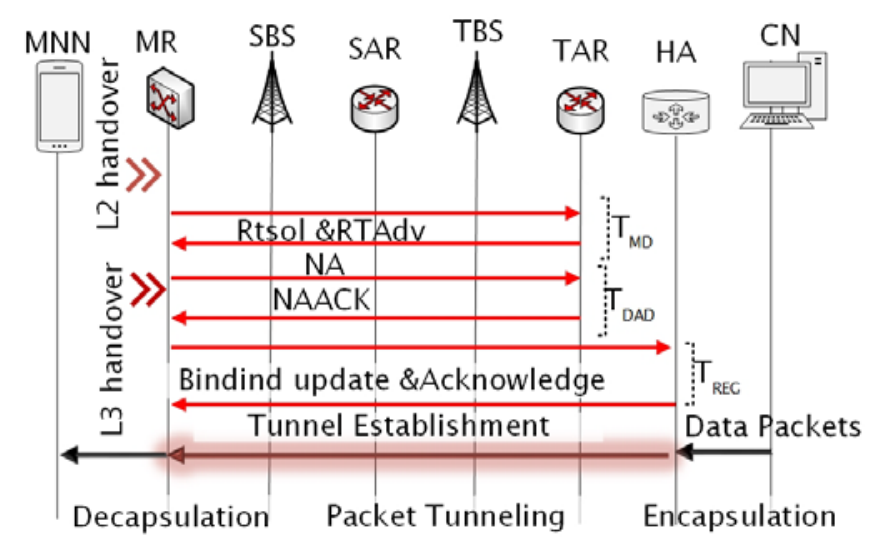

Fig. 2. NEMO BSP handover timing diagram [6]

\section{Architecture of proposed QoS-aware NEMO}

The procedure of handover occurs when a mobile network moves to a new point of attachment. This might cause a QoS degradation or force service termination if there are insufficient resources in the network. The proposed scheme introduces a dynamic resource allocation procedure which takes into account allocating bandwidth to users based on QoS requirements as well as the wireless channel conditions.

The proposed scheme combines fast handover techniques NEMO over WiMAX technology in order to ensure that the required QoS parameters can be achieved for High-Speed vehicles. The proposed protocol does not plan to replace the original handover mechanisms of the WiMAX standard. Instead, it attempts to cooperate with the layer 2 mechanisms to support connection with QoS considerations for mobile users. Moreover, it combines cross-layer mobility management and resource allocation to reduce handover latency and packet loss with an acceptable degree of QoS. 
Resource manager is added to the proposed protocol to keep track of resource reservation of the MNN and allocate a new resource. The resource manager is introduced as foreign mobility agents (FMAs). Fig. 3 illustrates the architecture of QoS-aware NEMO; it shows a mobile network which contains several levels of nested mobility agents. MNNs request resources. Then, the MR computes the aggregate QoS requirements, sends the information to Leaf-FMA, and propagates the QoS metrics to next hop until it reaches Root FMA. Root FMA has to perform admission control by accepting or rejecting the requests using Leaf-FMA information about radio channel resources. If there are sufficient resources, reservations are made for those services and are going to be assigned. If there are not enough resources, MRinfo_Reply message is sent to reject these requests. The negotiations for bandwidth allocation occur between the MNN and Root-FMA if they need to guarantee QoS requirements. In order to enhance the handover performance for the High-Speed vehicles, the proposed protocol provides two modes for fast handover: predictive mode and reactive mode. These two modes are determined according to whether a fast handover message is received on the previous link during the handover or not. The predictive mode is initiated when a layer 2 trigger occurs and it is bounded by non-optimized layer 2 delay in scanning phase. If predictive handover cannot be completed for any reasons the reactive mode is initiated.

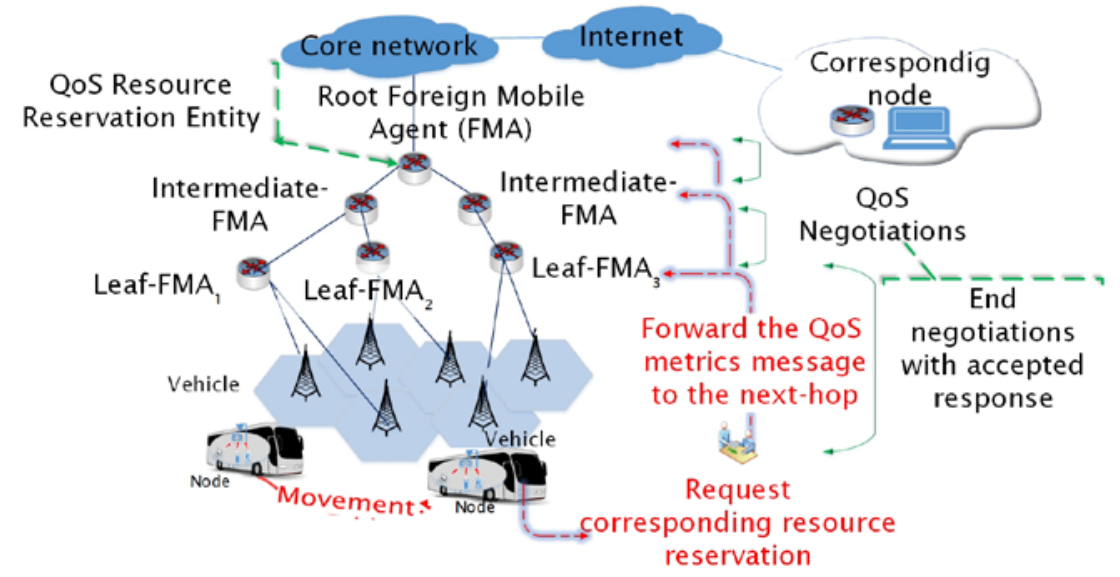

Fig. 3. Architecture of QoS-aware NEMO

Fig. 4 shows the predictive mode operation and its timing diagram. Layer 2 trigger is invoked when MR moves away from SBS and directed neighbourhood TBS. The cross point of the old and new connection acts as switching-FMA (SWF). MR sends the MOB_HO_IND message to its SBS when the predictive handover mode is initialized. As the SBS receives this message; it forwards MRHOnotify message to the TBS carrying the prefixes of the SBS and TBS in addition to resource allocation. The common FMA acts as SWF; which has direct connections with both SBS and TBS. Then SWF creates a new entry in its routing table to be able to redirect packets addressed for old prefix MR to the target BS. This new record for routing table will be propagated to every FMA on the path from the SWF towards the target. In addition, the leaf-FMA checks whether there are enough resources of the TBS. If so, it releases the channel recourse for SBS. Then it forwards the MRHOnotify to the TBS. Next; All packets destined for the old prefix MR are redirected to MNN through the TBS. MR gets a new prefix MR from the target leaf-FMA through RA message. Then, MNN performs the registration procedure to get its own IP through RA messages as in [14]. 


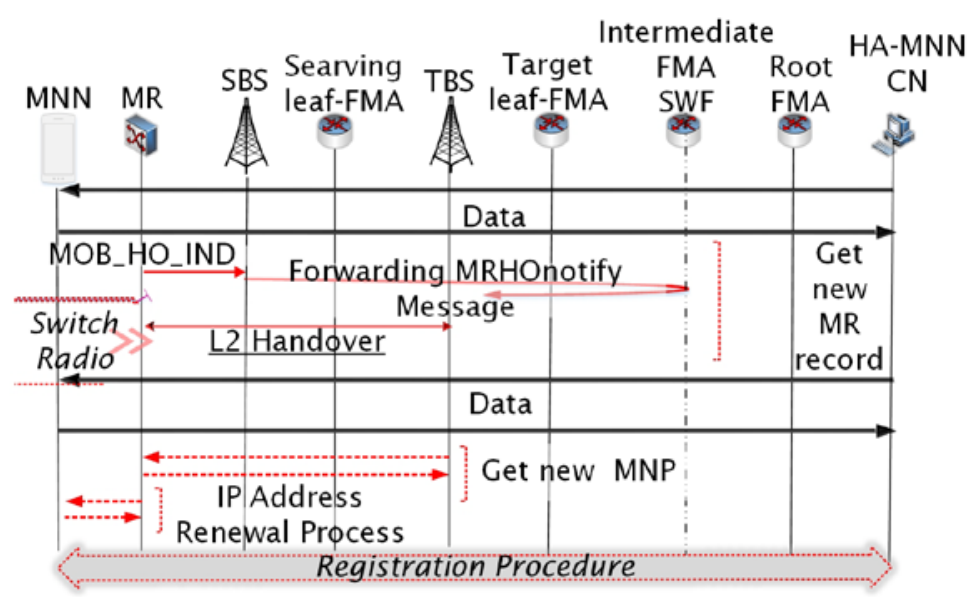

Fig. 4. QoS-aware NEMO predictive handover timing diagram

If predictive handover cannot be completed for any reason such as failing Layer 2 handover procedure, or the vehicle moves in an unexpected direction, the alternative mode is initiated. Fig. 5 illustrates the operation of reactive handover mode and its timing diagram. TBS starts reactive handover procedure by sending MRinfo message to its correspondent leaf-FMA. The target FMA forwards newMRquery message to all FMAs. A suitable FMA acts as SWF and stops forwarding the newMRquery. In addition to performing the QoS reservation fo-r MR, it also updates the routing tables by sending a newMRreply message along the path back to the target leaf-FMA with the new MR. This update redirects the packets from the old MNP and makes the corresponding QoS reservation.

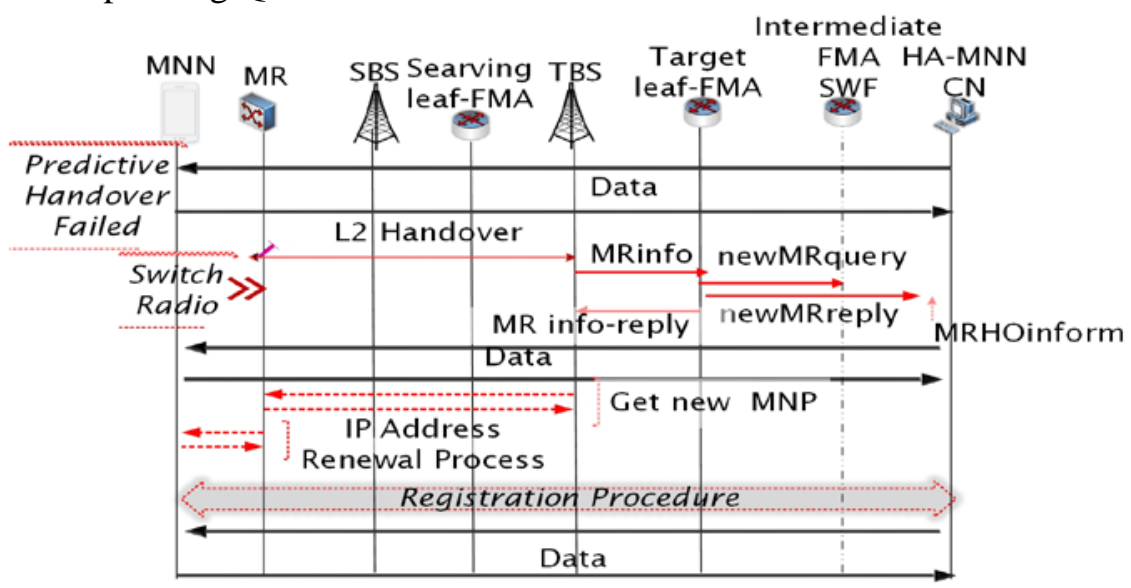

Fig. 5. QoS-aware NEMO reactive handover timing diagram

By Sending MRHOinfo message from SWF to the root-FMA, all information about handover consideration becomes available. When FMA receives the MRHOinfom message, it checks its routing table to see if it forwards the packets destined for the old MNP to the SWF. The MRinfo_reply message is sent to admit resource reservation. Then the MR gets a new prefix from the target leaf-FMA.

QoS-aware NEMO architecture defines a comprehensive set of principles for providing service guarantees for High-Speed vehicles based on WiMAX networks. It considers this registration procedure to assure no performance degradation of existing network mobility services. The messages exchanged during the process are shown in Fig. 6. MR needs to 
compute QoS requirements of its attached MNNs and send the required information to the BS. Alternatively, the BS sends MRinfo message to its correspondent leaf-FMA to get the QoS related information. Then the leaf-FMA sends new MRquery to the root-FMA with this information. The root FMA sends new MReply message through the intermediate FMAs to Serving leaf FMA. The MRreply message contains confirmation of QoS reservation. Now MR is serviced using this coverage area, and all the intermediate nodes on the transmission path are now ready to handle the mobile network's succeeding handovers. Next, the leaf-FMA sends MRinfo reply to the BS. Then MR gets a new MNP from the leaf-FMA by RAs.

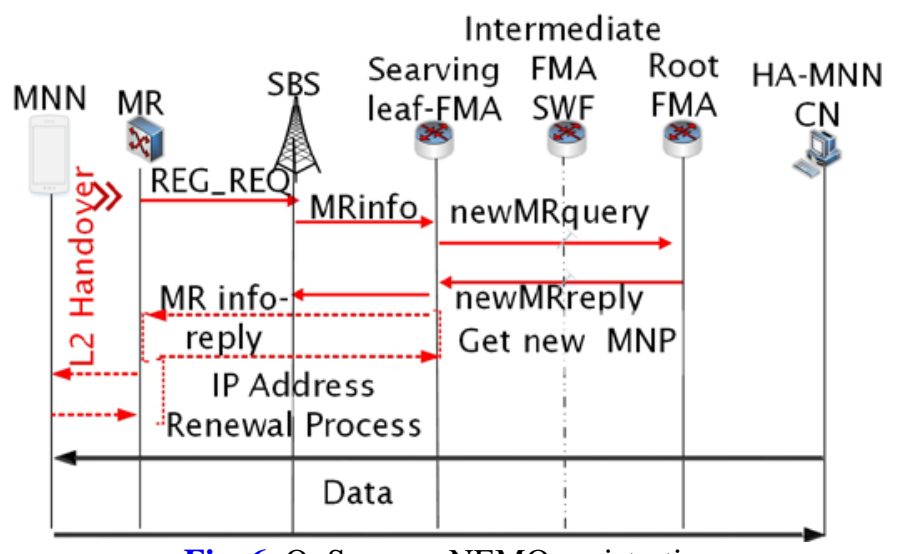

Fig. 6. QoS-aware NEMO registration

\section{Performance Analysis}

An analytical model is developed to investigate the handover performance for QoS-aware NEMO architecture. The considered metrics are packet loss, handover latency and signaling traffic overhead. The analytical framework compares between the proposed protocol and NEMO BSP in terms of the overall costs and the handover latency. Table 1 lists the notations used in the analytical model.

Table 1. List of notations

\begin{tabular}{|c|c|}
\hline Symbol & Meaning \\
\hline \hline$X$ & Horizontal dimension of CSM area \\
\hline$Y$ & Vertical dimension of CSM area \\
\hline $\mathrm{N}_{\mathrm{X}}$ & Numbers of horizontal roads in CSM model \\
\hline $\mathrm{N}_{\mathrm{Y}}$ & Destination apart of horizontal roads in CSM model \\
\hline $\mathrm{S}_{\mathrm{X}}$ & Destination apart of vertical roads in CSM model \\
\hline $\mathrm{S}_{\mathrm{Y}}$ & Expected epoch length \\
\hline $\mathrm{E}(\mathrm{L})$ & Expected epoch length in horizontal motion in CSM model \\
\hline $\mathrm{E}\left(\mathrm{L}_{\mathrm{X}}\right)$ & Expected epoch length in vertical motion in CSM model \\
\hline $\mathrm{E}\left(\mathrm{L}_{\mathrm{Y}}\right)$ & Average velocity of a vehicle \\
\hline $\mathrm{V}$ & Expected epoch time \\
\hline $\mathrm{E}(\mathrm{T})$ & Expected pause time \\
\hline $\mathrm{E}(\mathrm{U})$ & Maximum random pause time \\
\hline $\mathrm{U}_{\mathrm{max}}$ & Cell radius \\
\hline $\mathrm{R}$ & Average resident time in an AP in CSM model \\
\hline $\mathrm{T}_{\mathrm{r}}$ & The handover rate \\
\hline$\mu_{\mathrm{h}}$ &
\end{tabular}




\begin{tabular}{|c|c|}
\hline $\mathrm{P}_{\mathrm{pmf}}$ & The probability of the predictive mode failure \\
\hline$\lambda$ & The arrival rate of the MR into the overlapping area \\
\hline $\mathrm{T}_{\text {Early }}$ & $\begin{array}{c}\text { The time gained through the early registration in QoS-aware NEMO predictive } \\
\text { handover mode }\end{array}$ \\
\hline $\mathrm{T}_{\text {Handover }}^{\mathrm{NEMO}}$ & The overall handover latency in NEMO BSP \\
\hline $\mathrm{T}_{\mathrm{L} 2}$ & Link layer handover delay \\
\hline $\mathrm{T}_{\mathrm{L} 3}^{\mathrm{NEMO}}$ & Network layer handover delay in NEMO BSP \\
\hline $\mathrm{T}_{\mathrm{MD}}$ & Movement detection delay \\
\hline $\mathrm{T}_{\mathrm{DAD}}$ & Duplicate address detection delay \\
\hline $\mathrm{T}_{\mathrm{REG}}$ & Registration delay \\
\hline $\mathrm{t}_{\mathrm{w}}(\mathrm{L})$ & The wireless link delay for a packet with L length. \\
\hline$t_{d}(L)$ & The delay for one hop wired link with L length of packet \\
\hline $\mathrm{T}_{\text {Handover }}^{\text {QoS_NEMO }}$ & The overall handover latency in QoS-aware NEMO \\
\hline $\mathrm{T}_{\mathrm{L} 3}^{\mathrm{QoS} \_ \text {NEMO }}$ & Network layer handover delay in QoS-aware NEMO \\
\hline $\mathrm{T}_{\text {Predictive }}^{\mathrm{QoS} \text { NEMO }}$ & Handover delay in QoS-aware NEMO for predictive mode \\
\hline $\mathrm{T}_{\text {Reactive }}^{\text {QoS_NEMO }}$ & Handover delay in QoS-aware NEMO for Reactive mode \\
\hline $\mathrm{C}_{\mathrm{X}, \mathrm{Y}}$ & The transmission cost of a control packet between two nodes $\mathrm{X}$ and $\mathrm{Y}$ \\
\hline $\mathrm{C}_{\mathrm{BU}}^{\mathrm{NEMO}}$ & The signaling cost function for total binding update in NEMO BSP \\
\hline $\mathrm{C}_{\mathrm{MD}}$ & The signaling cost function for movement detection process \\
\hline $\mathrm{C}_{\mathrm{DAD}}$ & The signaling cost function for duplicate address detection process \\
\hline $\mathrm{C}_{\mathrm{REG}}$ & The signaling cost function for registration procedure \\
\hline $\mathrm{C}_{\mathrm{BU}}^{\mathrm{QoS} \_N E M O}$ & The signaling cost function for total binding update in QoS-aware NEMO \\
\hline $\mathrm{C}_{\mathrm{QoS} \_\mathrm{REG}}$ & The signaling cost function for registration in QoS-aware NEMO \\
\hline $\mathrm{C}_{\text {Predictive }}$ & The signaling cost function for predictive handover mode \\
\hline $\mathrm{C}_{\text {Reactive }}$ & The signaling cost function for reactive handover mode \\
\hline $\mathrm{C}_{\mathrm{PD}}^{\mathrm{NEMO}}$ & The packet delivery cost in NEMO BSP \\
\hline $\mathrm{n}_{\mathrm{MNN}}$ & Number of MNNs \\
\hline $\mathrm{C}_{\text {Tunnel }}$ & The packet tunneling cost \\
\hline $\mathrm{C}_{\text {Loss }}$ & The packet loss cost \\
\hline$\lambda_{\mathrm{m}}$ & Average packet arrval rate \\
\hline $\mathrm{C}_{\text {Data }}$ & The delivered data packets cost \\
\hline $\mathrm{H}$ & The ratio between cost of transferring data packet and control packet \\
\hline $\mathrm{C}_{\mathrm{PD}}^{\text {predictive? }}$ & The packet delivery cost in QoS-aware NEMO predictive handover mode \\
\hline $\mathrm{C}_{\text {Tunnel? }}^{\text {predictive }}$ & The packet tunneling cost in QoS-aware NEMO predictive handover mode \\
\hline $\mathrm{C}_{\text {Loss? }}^{\text {predictive }}$ & The packet loss cost in QoS-aware NEMO reactive handover mode \\
\hline $\mathrm{C}_{\mathrm{PD}}^{\text {Reactive? }}$ & The packet delivery cost in QoS-aware NEMO reactive handover mode \\
\hline $\mathrm{C}_{\text {Tunnel? }}^{\text {Reactive }}$ & The packet tunneling cost in QoS-aware NEMO reactive handover mode \\
\hline $\mathrm{C}_{\text {Loss? }}^{\text {Reactive }}$ & The packet loss cost in QoS-aware NEMO predictive handover mode \\
\hline $\mathrm{C}_{\mathrm{PD}}^{\mathrm{QoS} \_\mathrm{NEMO}}$ & The packet delivery cost in QoS-aware NEMO \\
\hline $\mathrm{PC}_{\mathrm{HA}}$ & The processing cost at the HA \\
\hline
\end{tabular}




\begin{tabular}{|c|c|}
\hline $\mathrm{PC}_{\mathrm{AR}}$ & The processing cost at the AR \\
\hline $\mathrm{PC}_{\mathrm{Root}_{\mathrm{FMA}}}$ & The processing cost at the Root-FMA \\
\hline $\mathrm{PC}_{\mathrm{MR}}$ & The processing cost at the MR \\
\hline $\mathrm{C}_{\mathrm{Total}}^{\mathrm{NEMO}}$ & The total cost in NEMO BSP \\
\hline $\mathrm{C}_{\mathrm{Total}}^{\text {QoS }} \mathrm{NEMO}$ & The total cost in QoS-aware NEMO \\
\hline
\end{tabular}

\subsection{Analytical Models}

The mobile service cells are assumed to have a hexagonal cellular architecture with equal size. CSM model is considered, as it can be used for public mobile networks deployed in a city for urban warfare. In this mobility model, MR movements must follow traffic regulations. So these regulations are considered in our mobility model. The area used in CMS model is presented as a grid of streets forming a particular section of a city. The allowed area is assumed to be a rectangular area of dimension $\mathrm{X} \times \mathrm{Y}$ as shown in Fig. 7 Where roads are parallel to axes [15- 17].

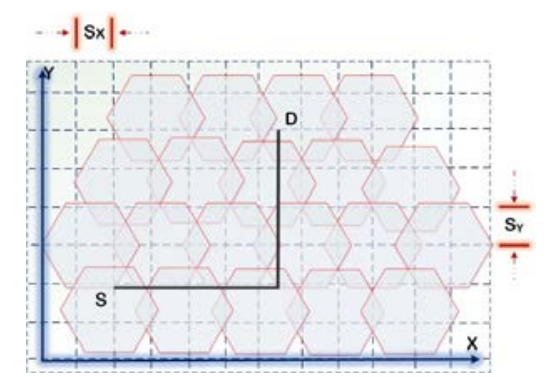

Fig. 7. CMS model [17]

The assumed road parameters are horizontal roads $S_{X}$ distance apart, and vertical roads $S_{Y}$ distance apart. $\mathrm{N}_{\mathrm{X}}$ and $\mathrm{N}_{\mathrm{Y}}$ are the numbers of horizontal and vertical roads respectively. Which can be evaluated as:

$$
\begin{aligned}
& \text { 쟍 }{ }_{\mathrm{X}}=\frac{\mathrm{X}}{\mathrm{S}_{\mathrm{X}}+1} \\
& \text { 쟞 } \mathrm{Y}=\frac{\mathrm{Y}}{\mathrm{S}_{\mathrm{Y}}+1}
\end{aligned}
$$

Therefore, the expected epoch length is formulated as follows [17]:

$$
\mathrm{E}(\mathrm{L})=\mathrm{E}\left(\mathrm{L}_{\mathrm{X}}\right)+\mathrm{E}\left(\mathrm{L}_{\mathrm{Y}}\right)
$$

where $\mathrm{E}\left(\mathrm{L}_{\mathrm{X}}\right)$ and $\mathrm{E}\left(\mathrm{L}_{\mathrm{Y}}\right)$ can be calculated as in [17] :

$$
\begin{gathered}
E\left(L_{X}\right)=\frac{X\left(x^{+}\right)}{3 x_{x} \text { 쟞 }} \\
E\left(L_{X}\right)=\frac{Y\left({ }_{y}+\right)}{3{ }_{y} \text { 잕 }}
\end{gathered}
$$


Then the expected epoch time with an average velocity of a vehicle (v) is calculated as:

$$
\mathrm{E}(\mathrm{T})=\frac{\mathrm{E}(\mathrm{L}) ?}{\mathrm{v}}
$$

As in [16]; Let there is a random pause time between 0 to $U_{\max }$ to avoid a collision at each road intersection for safety. So the expected pause time can be calculated by:

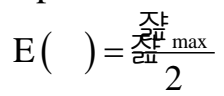

Let the radius $\mathrm{r}$ of each Acess Point (AP) be greater than the spacing between successive road segments. APs cover the road network of dimensions $\mathrm{X} \times \mathrm{Y}$. There are $\mathrm{n}$ rows of APs and $\mathrm{m}$ APs in each row so that $\mathrm{m} \times \mathrm{n}$ APs cover the rectangular area. So the radius of coverage area is $r$, and two successive APs overlap at lengths of $l_{x}$ and $l_{y}$ as maximum lengths of $L$ along its diameters, Therefore, $\mathrm{m}$ and $\mathrm{n}$ are given by [17]:

$$
\begin{array}{r}
\mathrm{m}=\frac{\mathrm{X}-2 \times \mathrm{r}+\mathrm{r} \sqrt{3}}{\mathrm{r} \sqrt{3}} \\
\mathrm{n}=\frac{2 \times \mathrm{Y}-\mathrm{r}}{3 \times \mathrm{r}}
\end{array}
$$

By using equation (4), (5) and the simplification formula in [17]:

$$
\begin{aligned}
\mathrm{K}_{1} \mathrm{~S}_{\mathrm{X}}=2 \times \mathrm{r}=\mathrm{S}_{\mathrm{Y}} \mathrm{K}_{2} \\
\mathrm{X}=\left(\mathrm{N}_{\mathrm{X}}-1\right) S_{X} ! \\
\mathrm{Y}=\left(\mathrm{Y}^{-}-\right.
\end{aligned}
$$

The expected number of APs crossing in an epoch can be obtained as [16, 17]:

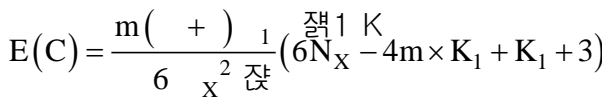

$$
\begin{aligned}
& +\frac{\mathrm{n}(\mathrm{n}+1) \mathrm{K}_{2}}{6 \mathrm{Y}^{2} \text { 잦 }}\left(6 \mathrm{Y}^{-} \times \mathrm{2}_{2}+{ }_{2}+\right)
\end{aligned}
$$

So the average residence time in an AP is formulated as in [17] :

$$
\mathrm{T}_{\mathrm{r}}=\frac{\mathrm{E}(\mathrm{T})+()}{\mathrm{E}(\mathrm{C}) ?} \times 360 \text { ㅈㅐㅐ }
$$

Therefore, the handover rate $\mu_{\mathrm{h}}$ can be obtained as in [17]:

$$
\mu_{\mathrm{h}}=\frac{1}{\mathrm{~T}_{\mathrm{r}}}
$$

The layer 2 trigger is used either to predict or rapidly respond to handover events as in predictive mode. Therefore additional messages may be exchanged between an MR and a Serving Acces Router (SAR), whereas the MR is in the overlapping area between the SAR and 
the TAR. The predictive mode will fail when the MR leaves the overlapping area before transmission of the additional signaling message may be completed. If the predictive mode fails, the reactive mode is activated. Therefore, the probability of the predictive mode failure $\mathrm{P}_{\mathrm{pmf}}$ has to be evaluated. By using $\mathrm{T}$ as a random variable for the time from the layer 2 trigger epoch to the downlink, $\mathrm{P}_{\mathrm{pmf}}$ can be represented by:

$$
\mathrm{P}_{\mathrm{Pmf}}=1-\mathrm{e}^{-\lambda \cdot \mathrm{T}_{\text {Early }}}
$$

where $\lambda$ is the arrival rate of the MR into the overlapping area [18]. $T_{\text {Early }}$ is the time gained through the early registration in predictive handover mode.

\subsection{Analysis of the Handover Latency}

In this section, the handover latency for NEMO-BSP and QoS-aware NEMO are analyzed. As in [13], the handover latency is defined as the time interval between the moment that the layer 2 trigger is initiated and the moment that the MNNs directly receive the first packet from the CNs in the new network. The overall handover latency in NEMO BSP can be considered as the summation of layer 2 and layer 3 latencies:

$$
\mathrm{T}_{\text {Handover }}^{\mathrm{NEMO}}=\mathrm{T}_{\mathrm{L} 2}+\mathrm{T}_{\text {짂 }}^{\mathrm{NEMO}}
$$

The overall latency in WiMAX handover process at layer 2 includes different phases. These phases make the overall handover latency dependent on used technology [19]. On the other hand; layer 3 handover latency consists of movement detection, address configuration, and registration. As shown in Fig. 2, it can be formulated as:

$$
\mathrm{T}_{\mathrm{L} 3}^{\mathrm{NEMO}}=\mathrm{MD}^{+} \mathrm{DAD}^{+}{ }_{\mathrm{REG}}{ }^{i}
$$

where Movement Detection delay ( $\mathrm{T}_{\mathrm{MD}}$ ) can be considered as the time needed for MR to discover that it has been disconnected from the HA and receiving its Router Advertisement (RA) message from TAR. Router Advertisement (RA) messages are broadcasted periodically by the TAR. The MR may proactively send Router Solicitation (RS) message to obtain the RA message from the TAR [20]. So $\mathrm{T}_{\mathrm{MD}}$ can be expressed as:

$$
\mathrm{T}_{\mathrm{MD}}={ }_{\mathrm{w}}(\mathrm{RS})+{ }_{\mathrm{w}}\left(\mathrm{RA}_{\mathrm{RA}}\right)_{\mathrm{c}}^{\mathrm{c}}
$$

Duplicate Address Detection delay $\left(\mathrm{T}_{\mathrm{DAD}}\right)$, is the care of address configuration. The $\mathrm{MR}$ obtains a care-of address by either stated or stateless address autoconfiguration. To perform this, the MR has to send out an NA message with its new CoA to check its uniqueness. Then, MR receives a NAACK message [6].Therefore, $\mathrm{T}_{\mathrm{DAD}}$ can be formulated as:

$$
\mathrm{T}_{\mathrm{DAD}}={ }_{\mathrm{w}}\left({ }_{\mathrm{NA}}\right)+{ }_{\mathrm{w}}\left(\text { NAAE }{ }^{\text {⿱ㅐK }}\right)
$$

Registration delay $\left(\mathrm{T}_{\mathrm{REG}}\right)$ is used for sending $\mathrm{BU}$ and receiving $\mathrm{BA}$. This delay is equal to the sum of the delays of all the links delay between MR and HA $[6,21]$. So the total registration delay can be considered as: 


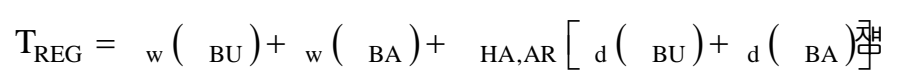

where $t_{d}(L)$ is the delay for one hop wired link with $L$ length of the packet.

The overall handover latency in QoS-aware NEMO can be expressed as:

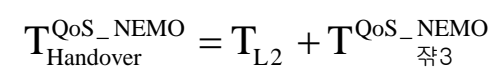

The probability of the predictive mode failure $\mathrm{P}_{\mathrm{pmf}}$ must be considered to derive the overall handover latency in QoS-aware NEMO. The overall handover latency for QoS-aware NEMO is obtained based on the two possible modes of handover. Fig. 4 and Fig. 5 show the two possible modes of the handover, which are performed during the proposed procedure. Hence $\mathrm{T}_{\mathrm{L} 3}^{\mathrm{QoS} \_ \text {NEMO }}$ can be defined as:

$$
\mathrm{T}_{\mathrm{L} 3}^{\mathrm{QoS} \_ \text {NEMO }}=\left(1-\mathrm{P}_{\mathrm{pmf}}\right) \mathrm{T}_{\text {Predictive }}^{\mathrm{QoS} \_ \text {NEMO }}+\mathrm{P}_{\mathrm{pmf}} \mathrm{T}_{\text {Reactive }}^{\text {QoS_NEMO }}
$$

where $T_{\text {Predictive }}^{\text {QoS_NEMO }}$ is the handover latency in the predictive mode, and it is shown in Fig. 4. $\mathrm{T}_{\text {Predictive }}^{\mathrm{QoS}}$ canO can be formulated as:

$$
\begin{aligned}
\mathrm{T}_{\text {Predictive }}^{\text {QOS_NEMO }} & =\mathrm{t}_{\mathrm{w}}\left(\mathrm{L}_{\text {MOB_HO_IND }_{-}}\right)+\mathrm{t}_{\mathrm{w}}\left(\mathrm{L}_{\text {MRHOnotify }}\right) \\
& + \text { ? }_{\text {Leaf }_{\text {FMA }}, \text { Root }_{\mathrm{FMA}}}\left[\mathrm{t}_{\mathrm{d}}\left(\mathrm{L}_{\text {MRHOnotify }}\right)\right]
\end{aligned}
$$

Fig. 5 presents the timing diagram associated with reactive handover mode. The elapsed time between Layer 2 handover trigger and the establishment of a new link can be expressed as:

$$
\begin{aligned}
& \mathrm{T}_{\text {Reactive }}^{\text {QOS_NEMO }}=\mathrm{t}_{\mathrm{w}}\left(\mathrm{L}_{\text {MRinfo }}\right)+\mathrm{t}_{\mathrm{w}}\left(\mathrm{L}_{\text {MRinfo-reply }}\right) \\
& +\mathrm{d}_{\text {Leaf }_{\text {FMA }}, \text { SWF }} \times \mathrm{t}_{\mathrm{d}}\left(\mathrm{L}_{\text {NewMRquery }}\right)+\mathrm{Pd}_{\text {SWF, ILeaf }}{ }_{\text {MMA }} \times \mathrm{t}_{\mathrm{d}}\left(\mathrm{L}_{\text {NewMRreply }}\right) \text { ? }
\end{aligned}
$$

Next sections represent the cost functions based handover procedure. Although the approach used here has the same structure as [6], the cost functions are developed based on the proposed formulations of the handover latency for QoS-aware NEMO protocol.

\subsection{Analysis of the Location Cost}

The cost function of the signaling overhead is investigated for NEMO BSP and QoS-aware NEMO. The location update cost is defined as the location update signaling overhead occurred during the handover, the product of the message length, and the hop distance. The transmission cost of a control packet between two nodes $\mathrm{X}$ and $\mathrm{Y}$ belonging to the wired part of a network can be expressed as $\mathrm{C}_{\mathrm{X}, \mathrm{Y}}=\tau \mathrm{d}_{\mathrm{X}, \mathrm{Y}}$, while the cost between two nodes in a wireless network can be represented as $\mathrm{C}_{\mathrm{MN}, \mathrm{AR}}=\tau \mathrm{z}$, where $\mathrm{d}_{\mathrm{X}, \mathrm{Y}}$ is the hop distance between the two network elements $X$ and $Y$. $\tau$ is the unit transmission cost over a wired link, and $\mathrm{z}$ is the weighting factor of the wireless link. Thus, the transmission cost in a wireless link is generally larger than the transmission cost in a wired link [2]. 
In NEMO BSP, location update cost function $\mathrm{C}_{\mathrm{BU}}^{\mathrm{NEMO}}$ is expressed as follows [21]:

$$
\mathrm{C}_{\mathrm{BU}}^{\mathrm{NEMO}}=\mu_{\mathrm{h}}\left(\mathrm{C}_{\mathrm{MD}}+\mathrm{C}_{\mathrm{DAD}}+\mathrm{C}_{\mathrm{REG}}\right)
$$

where $\mathrm{C}_{\mathrm{MD}}$, $\mathrm{DAD} \quad \mathrm{REG}$ are the cost for movement detection process, duplicate address detection delay, and registration procedures.

$$
\begin{array}{r}
\mathrm{C}_{\mathrm{MD}}=2 \times\left(\mathrm{C}_{\mathrm{MR}, \mathrm{AR}}+\mathrm{PC}_{\mathrm{AR}}+\mathrm{PC}_{\mathrm{MR}}\right) \\
\mathrm{C}_{\mathrm{DAD}}=\left(\mathrm{C}_{\mathrm{MR}, \mathrm{AR}}+\mathrm{PC}_{\mathrm{AR}}+\mathrm{PC}_{\mathrm{MR}}\right) \\
\mathrm{C}_{\mathrm{REG}}=2 \times\left(\mathrm{C}_{\mathrm{MR}, \mathrm{AR}}+\mathrm{C}_{\mathrm{AR}, \mathrm{HA}}+\mathrm{PC}_{\mathrm{AR}}+\mathrm{PC}_{\mathrm{HA}}\right)
\end{array}
$$

To derive QoS-aware NEMO update cost, The probability of the predictive mode failure is considered. Its value can reach 0 when handover is predicted successfully. Depending on the value of $\mathrm{P}_{\mathrm{Pmf}}$, the predictive and reactive mode can be activated. So, the location update cost can be represented as follows:

$$
\mathrm{C}_{\mathrm{BU}}^{\mathrm{QoS} \_\mathrm{NEMO}}=\mu_{\mathrm{h}}\left(\mathrm{C}_{\mathrm{QoS} \_ \text {REG }}+\left(1-\mathrm{P}_{\mathrm{pmf}}\right) \mathrm{C}_{\text {Predictive }}+\mathrm{P}_{\mathrm{pmf}} \mathrm{C}_{\text {Reactive }}\right)
$$

where $\mathrm{C}_{\mathrm{QOS} \_ \text {REG }}, \mathrm{C}_{\text {Predictive }}$, and $\mathrm{C}_{\text {Reactive }}$ are the location update for registration process, predictive and reactive mode respectively; the location update for registration process is formulated based on the required messages exchanged during the dynamic resource allocation procedure as in Fig. 6.

$$
\begin{aligned}
& \mathrm{C}_{\mathrm{QoS} \_\mathrm{REG}}=2 \times\left(\mathrm{C}_{\mathrm{MN}, \mathrm{MR}}+\mathrm{C}_{\mathrm{MR}, \mathrm{AR}}+\mathrm{C}_{\mathrm{AR}, \quad \text { FMA 잒 } e a f}\right.
\end{aligned}
$$

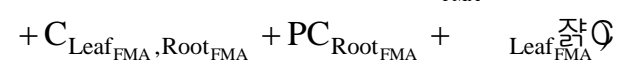

Referring to Fig. 4, and Fig. 5, location update costs for the two possible modes of handover are obtained as follows:

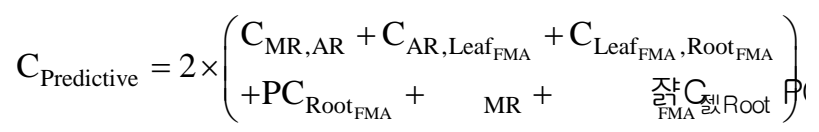

$$
\begin{aligned}
& \mathrm{C}_{\text {Reactive }}=2 \times\left(\mathrm{C}_{\mathrm{MR}, \mathrm{AR}}+\mathrm{C}_{\mathrm{AR}, \mathrm{Leaf}_{\mathrm{FMA}}}+\mathrm{C}_{\mathrm{Leaf}_{\mathrm{FMA}}, \mathrm{SWF}}+\mathrm{PC}_{\mathrm{SWF}}+\mathrm{MR} \text { ? }\right)
\end{aligned}
$$

\subsection{Analysis of the Packet Delivery Cost}

The packet delivery cost is introduced to analyze transmitted data packets due to delivery, tunneling, and packet loss during the handover. A tunneling cost occurs when the tunnel between the SAR and the TAR is used to forward packets. A packet loss cost occurs when packets are not prevented through tunneling and buffering during the handover. Each cost is calculated as the product of the data packet size, the hop distance, and the elapsed time.

The packet delivery cost is defined as the linear combination of packet tunneling cost (C Tunnel $)$ and packet loss cost $\left(\mathrm{C}_{\text {Loss }}\right)$ during handover latency. Let $\alpha$ and $\beta$ be weighting factors 
(where $\alpha+\beta=1$ ), which emphasize tunneling effect and dropping effect [2].

In NEMO BSP, the packet delivery cost is expressed as follows:

$$
\mathrm{C}_{\mathrm{PD}}^{\mathrm{NEMO}}=\mu_{\mathrm{h}} \times \mathrm{n}_{\mathrm{MNN}}\left(\alpha \mathrm{C}_{\text {Tunnel }}+\beta \mathrm{C}_{\text {Loss }}\right)
$$

In NEMO BSP all packets for MNN are lost during the handover as in the next equation:

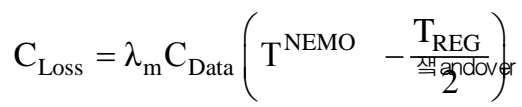

So the delivered data packets can be formulated as:

$$
\mathrm{C}_{\text {Data }}=\eta\left(\mathrm{C}_{\mathrm{CN}, \mathrm{HA}}+\mathrm{C}_{\mathrm{HA}, \mathrm{AR}}+\mathrm{C}_{\mathrm{AR}, \mathrm{MNN}}+\mathrm{PC}_{\mathrm{HA}}\right)
$$

where $\eta$ represents the ratio between the cost of transferring a data packet and the cost of transferring control and can be calculated as:

$$
\eta=s_{d} / s_{c}
$$

For NEMO BSP, there may be no buffering. Therefore, $\mathrm{C}_{\text {Tunnel }}$ will be equal to zero.

QoS-aware NEMO packet delivery costs in the predictive mode and reactive mode are defined also as the linear combination of packet tunneling cost and packet loss cost during handover latency. Then, the packet delivery cost for each mode is computed as follows:

$$
\mathrm{C}_{\mathrm{PD}}^{\text {predictive }}=\alpha \mathrm{C}_{\text {Tunnel? }}+\beta \mathrm{C}_{\text {Loss? }} \text { ? }
$$

There is no loss with QoS-aware NEMO during predictive handover mode. So the packet loss cost in this mode can be zero. Therefore, only packet tunneling cost is evaluated as follows:

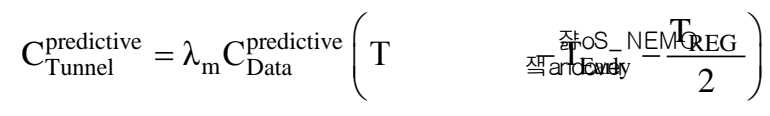

With similar reasoning to NEMO BSP, the cost of transferring data packets from $\mathrm{CN}$ to MNN for QoS-aware NEMO during predictive handover mode is given by:

$$
\begin{aligned}
\mathrm{C}_{\text {Data }}^{\text {predive? }}= & \eta\left(\mathrm{C}_{\mathrm{CN}, \mathrm{SAR}}+\mathrm{C}_{\mathrm{SAR}, \mathrm{Root}_{\mathrm{FMA}}}+\mathrm{C}_{\mathrm{Root}_{\mathrm{FMA}}, \mathrm{TAR}}\right. \\
& +\mathrm{C}_{\mathrm{TAR}, \mathrm{MR}}+\mathrm{C}_{\mathrm{MR}, \quad+\mathrm{PC}}{ }_{\mathrm{FMA}}, \text { 就 } \mathrm{NN}^{2}
\end{aligned}
$$

If MR leaves the overlapping area before transmission of the additional signaling message may be completed. The predictive mode will fail and the reactive mode will be activated. The packet delivery cost in reactive mode can be expressed as follows:

$$
\mathrm{C}_{\mathrm{PD}}^{\text {Reactive }}=\alpha \mathrm{C}_{\text {Tunnel }}+\beta \mathrm{C}
$$


During reactive handover mode, the packet tunneling cost can be zero. So, only packet loss cost occurs, and can be computed as follows:

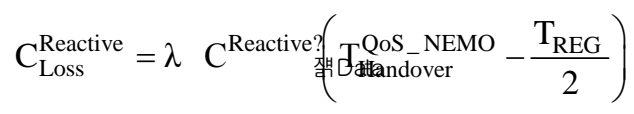

where $\mathrm{C}_{\text {Data }}^{\text {Reactive }}$ is the cost of transferring data packets from CN to MNN during reactive handover mode

$$
\mathrm{C}_{\text {Data }}^{\text {Reactive? }}=\eta\left(\mathrm{C}_{\mathrm{CN}, \text { Root }_{\mathrm{FMA}}}+\mathrm{C}_{\mathrm{Root}_{\mathrm{FMA}}, \mathrm{TAR}}+\mathrm{C}_{\mathrm{TAR}, \mathrm{MR}}+\mathrm{C}_{\mathrm{MR},}+\mathrm{PC} \quad{ }_{\mathrm{FMA}} \text { ? }\right)
$$

Finally, the total packet delivery cost in QoS-aware NEMO is computed as:

$$
\mathrm{C}_{\mathrm{PD}}^{\mathrm{QoS} \_\mathrm{NEMO}}=\mu_{\mathrm{h}} \times \mathrm{n}_{\mathrm{MNN}}\left(\left(1-\mathrm{P}_{\mathrm{pmf}}\right) \mathrm{C}_{\mathrm{PD}}^{\text {Predictive }}+\mathrm{P}_{\mathrm{pmf}} \mathrm{C}_{\mathrm{PD}}^{\text {Reactive }}\right)
$$

\subsection{Analysis of the total Cost}

Based on the aforementioned analysis on the location binding update cost, and packet delivery cost shown in Eqns. (26), (30), (34) and (46). For each protocol presented: NEMO BSP and QoS-aware NEMO, the total cost is expressed as follows [2]:

$$
\mathrm{C}_{\text {Total }}^{\mathrm{X}}=\mathrm{C}_{\mathrm{BU}}^{\mathrm{X}}+\mathrm{C}_{\mathrm{PD}}^{\mathrm{X}} \text { whe⿶e⿻上丨e? }: \quad \ni\{\quad\}
$$

\section{Numerical Results}

This section presents various analysis results based on the proposed analytical framework. The analysis involves studying the impact of QoS-aware NEMO on different types of cost functions. The proposed framework equations have been validated and applied using Matlab. There are various parameters should be considered in the analysis such as user's velocity, packet arrival rate and Session to Mobility Ratio (SMR) since they have a considerable impact on network performance. Finaly, QoS-aware NEMO is compared with other improvements to NEMO-BSP. Table 2 presents the values of the system's parameters used in the analysis. Parameters values were referenced from [22-25].

Table 2. System parameters values

\begin{tabular}{|c|c|}
\hline System Parameter & Value \\
\hline $\mathrm{T}_{\mathrm{L} 2}$ & $50 \mathrm{~ms}$ \\
\hline $\mathrm{T}_{\mathrm{DAD}}$ & $500 \mathrm{~ms}$ \\
\hline$\lambda_{\mathrm{m}}$ & 1 packet/ms \\
\hline $\mathrm{L}_{\mathrm{BU}}$ & 80 byte \\
\hline $\mathrm{L}_{\mathrm{BA}}$ & 40 byte \\
\hline $\mathrm{L}_{\text {MOB_HO_IND }}$ & 85 byte \\
\hline $\mathrm{L}_{\text {MRHOnotify }}$ & 52 byte \\
\hline
\end{tabular}




\begin{tabular}{|c|c|}
\hline $\mathrm{T}_{\mathrm{RA}}$ & $30 \mathrm{~ms}$ \\
\hline $\mathrm{S}_{\mathrm{x}}$ & $200 \mathrm{~m}$ \\
\hline $\mathrm{S}_{\mathrm{y}}$ & $200 \mathrm{~m}$ \\
\hline $\mathrm{K}$ & 5 \\
\hline $\mathrm{V}$ & $60,200 \mathrm{Km} / \mathrm{h}$ \\
\hline $\mathrm{U}_{\max }$ & $2 \mathrm{sec}$ \\
\hline $\mathrm{S}$ & $36 \mathrm{Km}$ \\
\hline $\mathrm{D}$ & $24 \mathrm{Km}$ \\
\hline
\end{tabular}

\subsection{Mobility Model}

CMS model is used to simulate the movements of vehicles in any city that consists of building blocks and streets. In this model, mobiles can only move in streets. Depending on this mobility model, the handover rate $\mu_{\mathrm{h}}$ and the probability of predictive mode failure are evaluated as a function of cell radius and user velocity [25-27]. Vehicles travel at a higher speed in a freeway scenario but also may move with limited speed inside the city. Therefore. Two values of velocity are analyzed, which are 60 and $200 \mathrm{~km} / \mathrm{h}$. Each base station has a maximum cell radius equal to $350 \mathrm{~m}$ for the WiMAX infrastructure as in [28, 29].

Fig. 8 and Fig. 9 show the impact of cell radius on the $\mu_{\mathrm{h}}$ and $\mathrm{P}_{\mathrm{pmf}}$. Results represent that there is an increase in the rate of the handover when there is an increase in cell radius. Results also show that when the vehicle speed increases, the probability of predictive mode failure increases, which, in turn, reduces the amount of data received by vehicles.

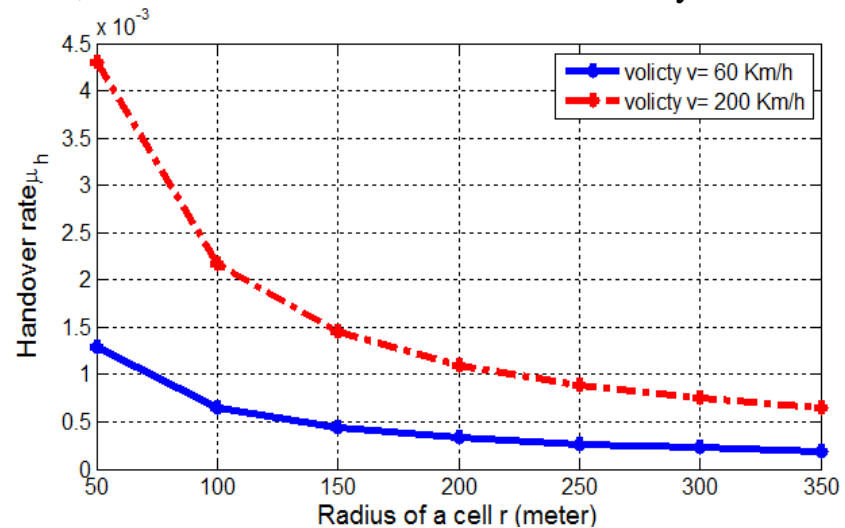

Fig. 8. Handover rate as a function of cell radius

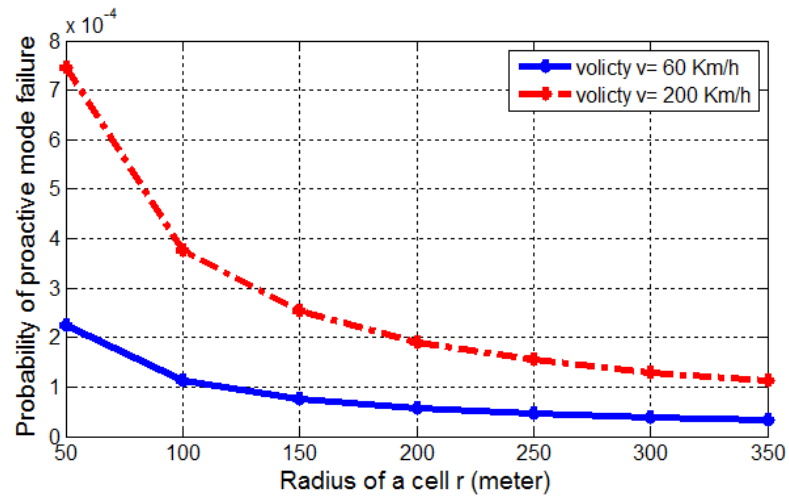

Fig. 9. Probability of predictive mode failure as a function of cell radius 


\subsection{Handover Latency}

The handover latency is an important indicator of the effectiveness of proposed handover procedure. The main difference between overall handover latency for NEMO BSP and QoS-aware NEMO is the signaling overhead occurred during handover.

Fig. 10 shows that the latency increases as the number of signaling overhead increases. The number of signaling overhead increases proportionally with the levels number in network architecture. The figure also shows that the proposed protocol reduced the signaling message by $65 \%$ compared with NEMO BSP.

\subsection{Location Update Cost}

Fig. 11 depicts location update cost variation when the MNN's mean velocity is changed with different values of cell radius in the case of CSM mobility model. As expected, the MNN performs fewer movements as the mean velocity of the MNN decreases. It is shown that the location update cost increases as the average velocity increases since the MNN with a higher average velocity has a higher domain crossing rate.

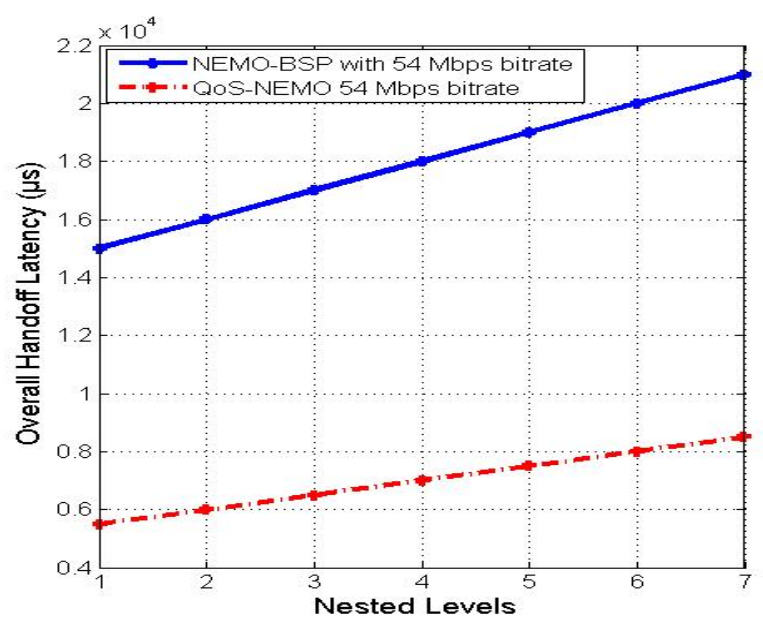

Fig. 10. Overall handover latency as a function of nested level

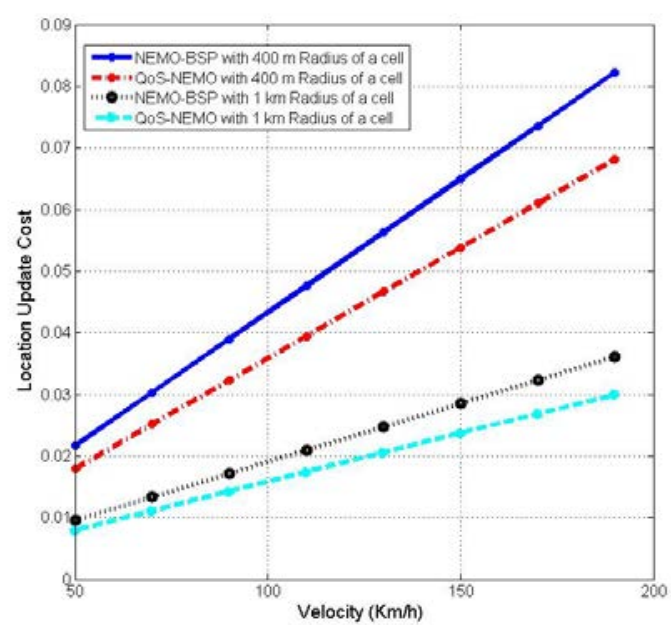

Fig. 11. Location update cost as a function of mean velocity 
In general, the location update cost is affected by the user mobility. So as the cell radius increases, the location update cost decreases. Therefore, the location update cost is inversely proportional to cell radius. Fig. 12 shows location update cost variation with cell radius with different MNN velocities.

\subsection{Packet Delivery Cost}

The packet delivery cost depends on the number of users. Therefore, the packet delivery cost increases as the number of MNNs increases. Fig. 13 shows that the packet delivery cost increases linearly as the number of MNNs increases. The impact of packet arrival rate on the packet delivery cost is shown in Fig. 14. It shows that the packet delivery cost increases proportionally with the packet arrival rate $\lambda_{\mathrm{m}}$. So, the proposed scheme becomes more efficient when $\lambda_{\mathrm{m}}$ increases as it reduces the packet loss cost for MNN with high speed.

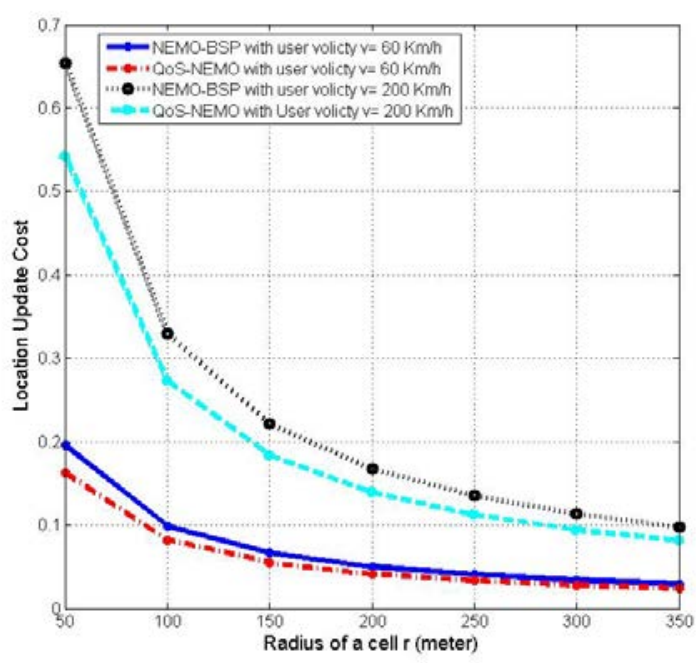

Fig. 12. Location update cost as a function of cell radius

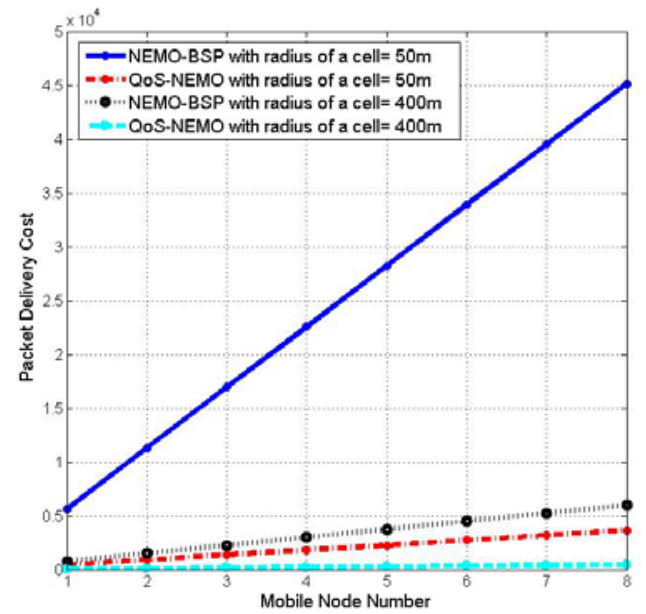

Fig. 13. Packet delivery cost as a function of MNN number 


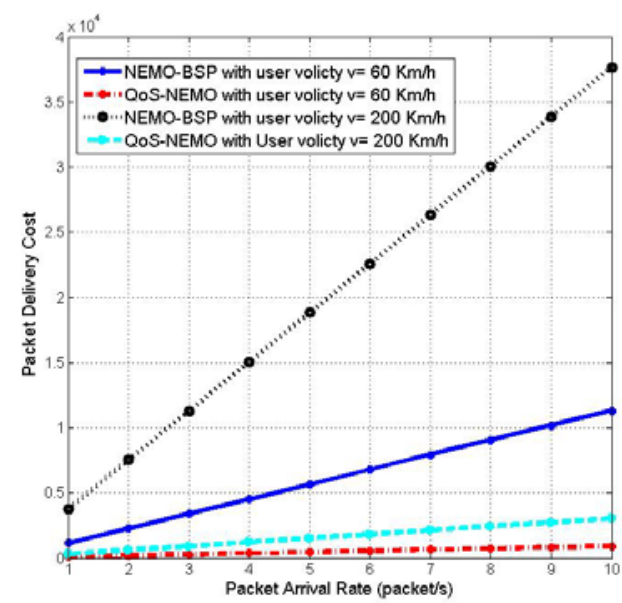

Fig. 14. Packet delivery cost as a function of packet arrival rate

\subsection{Total Cost}

Total cost combines the location update cost and the packet delivery cost. Fig. 15 shows the total cost as a function of SMR in CSM mobility model. The SMR is equal to $\lambda_{\mathrm{m}} / \mu_{\mathrm{h}}$ which is the packet arrival rate divided by the handover rate. In the case of SMR $\leq 1$, the location update cost becomes dominant in the total cost. Since the mobility rate is highly effective in the total cost than the transmission rate. However, at SMR $>1$, the transmission rate is larger than mobility rate and then, binding update is less performed and signaling overhead is decreased. So the impact of the location update cost is reduced, while the packet delivery becomes more effective.

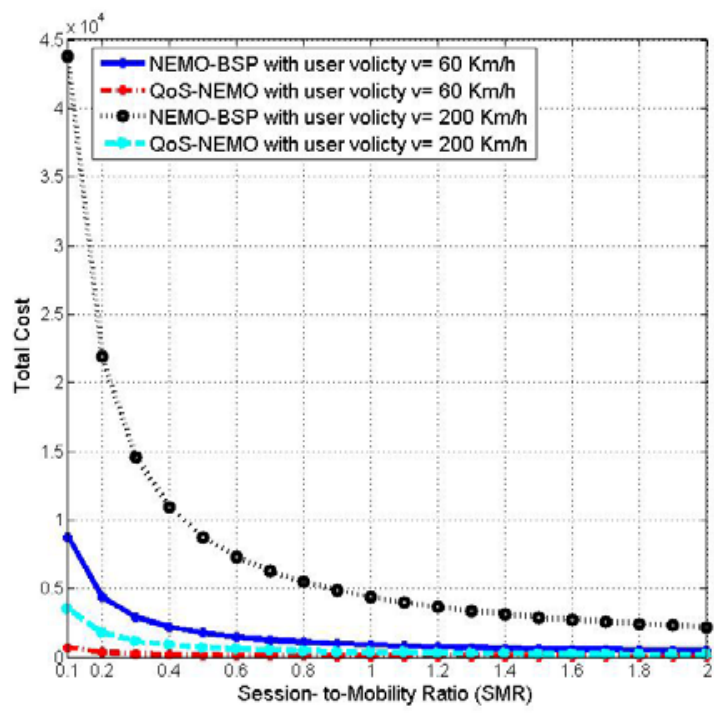

Fig. 15. Total cost as a function of SMR. 


\subsection{Comparison between QoS-aware NEMO and other NEMO-BSP improvements}

In this section, QoS-aware NEMO protocol is compared with three other improvements to NEMO-BSP. The three improvements are EfNEMO [6], FRONEMO [7], and MEN-NEMO $[9,10]$. EfNEMO uses a tentative binding update procedure to get a new NCoA before the layer 2 handover in order to minimize the handover latency. EfNEMO was chosen as it also uses the same mobility model concerning the probability of predictive mode failure. FRONEMO aims to reduce the handover latency by using IP pre-fetching and advance-registration to acquire CoA for the next cells. MEN-NEMO is LTE femtocell-based network mobility scheme, which aims to support seamless handover for high-speed trains. Both FRONEMO and MEN-NEMO were included in the comparison to verify the effectiveness of the designed handover procedure. The comparison focused on the common performance metrics that are presented in $[6,7,9,10]$. These metrics include the probability of predictive mode failure and handover latency.

Fig. 16 shows the probability of predictive mode failure for QoS-aware NEMO and EfNEMO as a function of cell radius. The figure illustrates that QoS-aware NEMO has a lower probability of predictive mode failure, as EfNEMO uses additional signaling messages that may cause the mode to fail if the MR leaves the coverage area before the transmission completes. While QoS-aware does not need additional signaling messages, as it uses the same layer 2 handover triggering message.

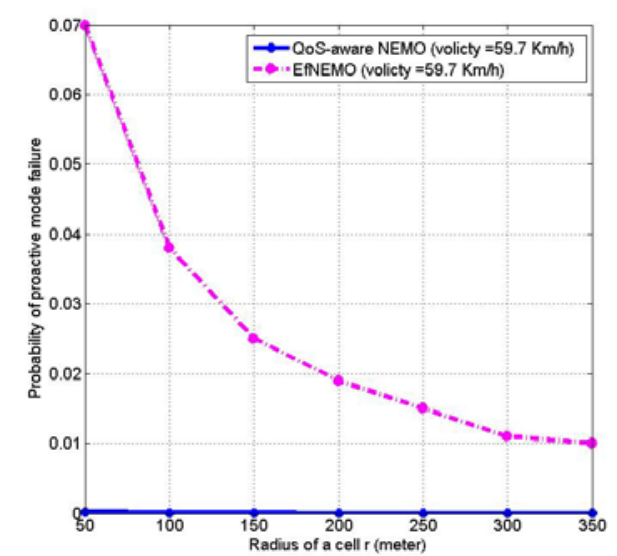

Fig. 16. The probability of predictive mode failure for QoS-aware NEMO and EfNEMO

The handover latency for NEMO-BSP, QoS-aware NEMO, FRONEMO, and MEN-NEMO is shown in Fig. 17. The figure shows that both QoS-aware NEMO and MEN-NEMO maintain the lowest handover latency. QoS-aware NEMO has a slightly lower curve than MEN-NEMO, as it starts the handover initialization procedure as early as possible. On the other hand, FRONEMO only outperforms NEMO-BSP at higher velocities. 


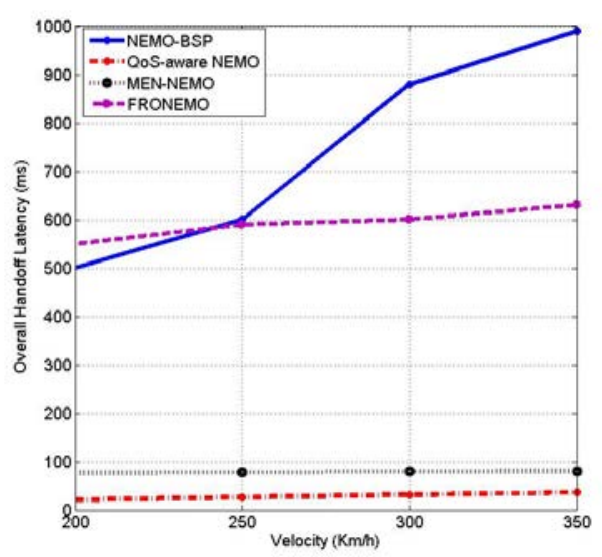

Fig. 17. The handover latency for NEMO-BSP, QoS-aware NEMO, FRONEMO, and MEN-NEMO

\section{Conclusion}

The paper proposed a dynamic resource allocation procedure supporting cross-layer handover techniques over NEMO infrastructure. The proposed handover protocol provides the required QoS parameters for the MNNs, which is important for communications in High-Speed vehicles. The proposed scheme managed to reduce the packet loss for high velocity by initiating handover messages with layer 2 actual handover phase and using the same control message to disconnect from the SBS and switch to TBS. Therefore, it requires less cost than the one required for basic support protocol with signaling reduction. The performance of both QoS-aware NEMO and NEMO BSP are evaluated in terms of handover latency, packet delivery cost and location update cost. The numerical results showed that QoS-aware NEMO achieved an improvement in the handover delay reached about $65 \%$. This proves that the proposed scheme provides awareness for designers on how to realize a QoS-aware resource management mechanism which is an essential demand for mobile users in High-Speed vehicles. Future work includes considering resource management for different types of traffic like voice, audio and video. Future research would consider implementing the spatial network performance in QoS-aware NEMO by migrating from WiMAX to Long Term Evolution (LTE) technology.

\section{References}

[1] W. Xiaonan, and Z. Shan, "Research on mobility handover for IPv6-based MANET," Trans. Emerging Tel Tech, vol. 25, pp. 679-691, 2014. Article (CrossRef Link).

[2] H. Nashaat and R. Rizk, "Handover management based on location based services in F-HMIPv6 Net-works,” KSII Transactions on Internet and Information Systems, vol. 9, no. 12, pp. 5028-5057, 2015. Article (CrossRef Link).

[3] C. Anagnostopoulos, K. Kolomvatsos, and S. Hadjiefthymiade, "Efficient location based services for groups of mobile users," in Proc. of IEEE $14^{\text {th }}$ International Conference on Mobile Data Management (MDM), Italy, pp. 6-15, June 2013. Article (CrossRef Link).

[4] H. Nashaat, R. Rizk and H. Mahdi, "A robust analytical model of mobile IP handover with multiple traffic profile,” International Journal of Wireless Information Network, Springer, vol. 18, no. 4, pp. 210-223, 2011. Article (CrossRef Link). 
[5] B. Sardar and D. Saha, "Performance analysis of NEMO basic support protocol (BSP) in nested network mobility (NeNEMO)," International Conference on Advances in Computing, pp. 1430-1435, 2013. Article (CrossRef Link).

[6] S. Ryu, K. Joon-Park and J. Choi, "Enhanced fast handover for network mobility in intelligent transportation system,” IEEE Transactions on Vehicular Technology, vol. 63, Issue 1, January 2014. Article (CrossRef Link).

[7] A. Mitra, B. Sardar and D. Saha, "Fast and route optimized NEMO (FRONEMO) proposal to improve handoff performance in network mobility," in Proc. of IEEE Explore, Conference on Control Communication and Computing (ICCC), December 2013. Article (CrossRef Link).

[8] C.Wei Lee, Y. Sun and M. Chen, "Protocol and architecture supports for network mobility with QoS-handover for high-velocity vehicles,” Wireless Networks, vol. 19, no 5, pp. 811-830, July 2013. Article (CrossRef Link).

[9] C.Wei Lee, M.Chen, M. Chen, and Y. Sun, "Seamless handover for high-speed trains using femtocell-based multiple egress network interfaces," IEEE Transactions on Wireless Communications, vol. 13, no. 12, pp. 6619-6628, October 2014. Article (CrossRef Link).

[10] D. Girhepunje and H. Bhute, "Implementation of seamless handover in high speed train using LTE femtocell," International Journal of Innovative Research in Computer and Communication Engineering, vol. 4, no. 6, pp. 12557-12566, June 2016. Article (CrossRef Link).

[11] X. Luo, "Delay-oriented QoS-aware user association and resource allocation in heterogeneous cellular networks," IEEE Transactions on Wireless Communications, vol. 16, no. 3, pp. 1809-1822, March 2017. Article (CrossRef Link).

[12] L. Hussein, A. Hashim, W. Hassan. and M. Habaebi, “A QoS awareness scheme sustaining seamless handover for network mobility," in Proc. of The $3^{\text {rd }}$ International Conference on Computer Engineering \& Mathematical Sciences (ICCEMS 2014), Langkawi, Malaysia, 2014. Article (CrossRef Link).

[13] L. Hussein, A. Hashim, M. Habaebi and A. Zeki, "Performance comparison of (Diff-FH NEMO) scheme in IPv6-based network mobility,” in Proc. of International Conference on Computer and Communication Engineering (ICCCE), Kuala Lumpur, pp. 288-293, 2016. Article (CrossRef Link).

[14] I. Soto, CJ. Bernardos, M. Calderon, A. Banchs and A. Azcorra. "NEMO-Enabled Localized Mobility Support for Internet Access in Automotive Scenarios,”IEEE Communications Magazine, vol. 47, no. 5, pp. 152-159, May 2009. Article (CrossRef Link).

[15] M. Hossain and M. Atiquzzaman, "Stochastic properties and application of city section mobility model," in Proc. of IEEE Explore, Global Telecommunications Conference (GLOBECOM), November-December 2009. Article (CrossRef Link).

[16] M. Hossain and M. Atiquzzaman, "Signaling cost analysis of mobility protocols using city section mobility model," in Proc. of $2^{\underline{n} d}$ International conference on computer science and application, Korea, December 2009. Article (CrossRef Link).

[17] M. Hossain and M. Atiquzzaman, "Cost analysis of mobility protocols," Tele commination System, vol. 52, no. 4, pp. 2271-2285, April 2013. Article (CrossRef Link).

[18] S. Ryu, , J. Choi and K. Park, "Performance evaluation of improved fast PMIPv6-based network mobility for intelligent transportation systems,” Journal of Communications and Networks, vol. 15, pp. 142-152, 2013. Article (CrossRef Link).

[19] A. SafaSadiq, K. Abu Bakar, K. Ghafoor, J. Lloret and R. Khokhar, "An intelligent vertical handover scheme for audio and video streaming in heterogeneous vehicular networks," Mobile Networks and Applications, vol. 18, Issue 6, pp. 879-895, December 2013. Article (CrossRef Link).

[20] S. Islam, A. Hassan, R. Saeed, O. Khalifa, M. Hasan, O. Mahmoud, J. Daoud, and S. Hameed, "Mobility management schemes in NEMO to achieve seamless handoff: A qualitative and quantitative analysis," Australian Journal of Basic and Applied Sciences, vol. 5, no. 60, pp.390-402, 2011. Article (CrossRef Link). 
[21] A. Shahriar, M. Hossain and M. Atiquzzaman, "A cost analysis framework for NEMO prefix delegation-based schemes,” IEEE Transactions on Mobile Computing, vol. 11, no 7, July 2012. Article (CrossRef Link).

[22] O. Lee, J. Bonnin, I. You and T. Chung, "Comparative handover performance analysis of IPv6 mobility management protocols,” IEEE Transactions on Industrial Electronics, vol. 60, no. 3, pp. 1077-1088, March 2013. Article (CrossRef Link).

[23] M. Skorepa and R. Klug, "Enhanced analytical method for IP mobility handover schemes cost evaluation,” Telecommunication Systems, vol. 52, no. 3, pp. 1573-1582, March 2013. Article (CrossRef Link).

[24] S. Matinkhah, S. Khorsandi and S.Yarahmadian, "A new handoff management system for heterogeneous wireless access networks,” Wiley Online Library, April 2012. Article (CrossRef Link).

[25] S. Ryu, K. Lee and Y. Mun, "Optimized fast handover scheme in mobile IPv6 networks to support mobile users for cloud computing,” Journal of Supercomputing, vol. 59, no. 2, pp. 658-675, February 2012. Article (CrossRef Link).

[26] X. Ge, J. Ye, Y. Yang and Q. Li, “ User mobility evaluation for 5G small cell networks based on individual mobility model,” IEEE Journal on Selected Areas in Communications, vol. 34, pp. 528-541, 2016. Article (CrossRef Link).

[27] O. Karimi, J. Liu and C. Wang, "Seamless wireless connectivity for multimedia services in high speed trains," IEEE Journal on Selected Areas in Communications(JSAC), vol. 30, no. 4, pp. 729-739, May 2012. Article (CrossRef Link).

[28] M. Ben-Mubarak, B. Ali, N. Noordin, A. Ismail and C. Ng, "Mobile station Movement Direction Prediction (MMDP) based handover scanning for mobile WiMAX system," International Journal of Wireless personal communications, Springer, vol.73, pp. 839-865, 24 May 2013. Article (CrossRef Link).

[29] A. Ilyas, M. Aman, and N. Saeed, "Delay analysis of an improved WiMAX Macro-Femto handover technique and cell selection algorithm," International Journal of Wireless personal communications, Springer, vol. 85, pp. 2157-2168, 2015. Article (CrossRef Link). 


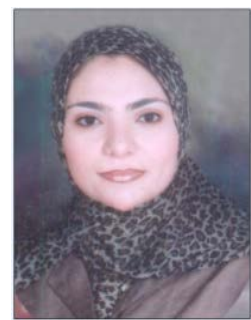

HebaNashaat is an assistant professor in the Electrical Engineering Department, Port Said University, Egypt. She got her B.Sc. and M.Sc. degrees in computer and control engineering, Suez Canal University in 2001 and 2006, respectively. Her Ph.D. degree in computer and control engineering is obtained from Port Said University in 2011. Worked as an executive director of Network Infrastructure, Port Said University from 2014 to 2016. Recently working as an executive director of Software Engineering Unit (SWEU) in Faculty of Engineering, Port Said University. Her research interests are in the area of computer networking, including mobile networks, handovers, and cloud computing. 